\title{
Blood Lead Level of Children and its Trend in Mitrovica, Kosova
}

\author{
Driton Shabani ${ }^{1}$ Ardiana Murtezani ${ }^{2}$ Bernard Tahirbegolli ${ }^{3}$ Adnan Bozalija $^{1}$ Edita Alili-Idrizi ${ }^{4}$ \\ Zana Ibraimi ${ }^{1}$
}

${ }^{1}$ Department of Pharmacy, Faculty of Medicine, University of Prishtina, Prishtina, Kosova

2 Physical Medicine and Rehabilitation Clinic, University Clinical

Center of Kosova, Prishtina, Kosova

3 Professional Education in Health/Vocational Field Nursing, Heimerer

College, Prishtina, Kosova

${ }^{4}$ Department of Pharmacy, Faculty of Medicine, State University of

Tetovo, Tetovo, Macedonia

J Child Sci 2019;9:e84-e89.
Address for correspondence Zana Ibraimi, PhD, Department of Pharmacy, Faculty of Medicine, University of Prishtina, St. "Bill Klinton" L5, H5, No28, 10000 Prishtina, Republic of Kosova (e-mail: zibraimi@yahoo.com).

\begin{abstract}
Keywords

- blood lead levels

- children

- lead mining and smelting

Environmental exposure to lead is considered to be one of the most important hazards to the health of children. Most commonly exposed are those who are poor and live in developing countries. The environmental lead pollution problem in the Roma Mahala neighborhood of Mitrovica was discovered through the appearance of high blood lead levels (BLLs) in children living there. The aim of our study was to investigate the BLLs in children according to gender, age, and area of residence. This study describes the results from a 7-year retrospective study (January 2010-April 2017) based on BLLs conducted on children aged 0 to 13 years living in all three districts of Mitrovica. The survey included 331 children. Blood lead analysis was performed in the laboratory using capillary and venipuncture samples tested by anodic stripping voltammetry using LeadCare II machines. Mean BLLs were the highest in the Roma Mahala with $23.6 \mathrm{mg} / \mathrm{dL}$ (standard deviation $\pm 15.9 \mu \mathrm{g} / \mathrm{dL}$ ). We obtained a statistical significance $(p<0.0001)$ between BLLs according to the settlements. The mean BLLs was higher in the 3 to 4 years aged children group in comparison with other age groups $(p=0.009)$. In none of the age groups with the Mann-Whitney test we obtained a significant gender difference on BLL $(p>0.05)$. Lead poisoning levels continue to be a serious problem among children living in Mitrovica over the past several years due to heavy lead pollution. All children from this region should receive environmental evaluations and medical examinations.
\end{abstract}

\section{Introduction}

Lead poisoning is an old and significant public health problem throughout the world. ${ }^{1,2}$ Toxicity correlates with lead concentration in blood and progresses from biochemical and subclinical abnormalities, at levels around $10 \mu \mathrm{g} / \mathrm{dL}$, to coma and death at levels of more than $100 \mu \mathrm{g} / \mathrm{dL}^{3-5}$ Elevated blood

received

February 11, 2019

accepted after revision

May 23, 2019
DOI https://doi.org/

10.1055/s-0039-1693515. ISSN 2474-5871. lead is also associated with neurodevelopment abnormalities including attention-deficit disorders, behavioral disturbances, learning disabilities, and deficits in fine and gross development. ${ }^{6-9}$ Impairment of intelligence quotient occur at even lower levels of exposure $(1 \mu \mathrm{g} / \mathrm{dL})^{2,10,11}$

Due to local lead mining and processing, environmental exposure to lead is considered one of the most important 
hazards to the health of children. ${ }^{12}$ Most susceptible are the children, and most commonly exposed are those who are poor and live in developing countries. ${ }^{13}$ In many developing countries where leaded gasoline is no longer used, many children and workers are exposed to fugitive emissions and mining wastes. ${ }^{14}$ Nutritional deficiencies faced by children living in poverty, enhance lead's absorption and/or effects. Low calcium, iron, zinc, and vitamin $\mathrm{C}$ intake are examples of nutrients that influence the availability and toxicity of lead. ${ }^{15}$

Health concerns related to lead in Kosovo come from lead emissions in the air and water from lead and zinc mines and lead processing plants, in particular lead smelters. ${ }^{16,17}$ The emissions are spread over miles of latitude, which are known as hot spots. Kosovo has some lead and zinc mines, mainly in northern Mitrovica. ${ }^{18}$ A lead smelter has been working for decades in Zveçan (several kilometers north from Mitrovica) until the end of 2000 when it was closed. So Zveçan and Mitrovica are hot spots as regards the presence of lead. ${ }^{19}$ Lead emissions in the air have dropped significantly since the Zveçan crusher closure, but lead and sterile mines still contaminate the air (breathable dust), water, and soil (rainfall precipitation and dust deposits). ${ }^{20,21}$ Similarly, the land around Zveçan, which is still contaminated by lead deposits, is a major source of exposition risk.

The city of Mitrovica is one of the most polluted cities in the region due to the mining and metallurgical activities of the "Trepça" industrial complex. ${ }^{16}$ The following industrial plants of the "Trepça" complex contributed to the pollution and poisoning of the environment in Mitrovica and its surroundings: the smelter, the refinery, the flotation, the factory of chemical products, the fryer, the lead and zinc refinery, the power plant, the zinc electrolysis, the battery factory, and the equipment plant for disposal of medical material and medicines.

The environmental lead pollution problem in the Roma Mahala neighborhood of Mitrovica was presented through the appearance of high blood lead levels (BLLs) in children living there. Lead analyses on environmental samples were performed at the same time to identify the possible sources of lead (e.g., drinking water, soil, and air). ${ }^{12,17}$ It is essential for children suffering from lead poisoning to have regular follow-up examinations, and specifically need their BLLs to be monitored. ${ }^{17}$

The aim of our study is to investigate the BLL in children according to gender, age, area of residence, and its trend within the years.

\section{Materials and Methods}

\section{Study Design}

This study describes the results from a 7-year retrospective study (January 2010-April 2017) based on BLLs in children aged 0 to 13 years living in all three districts of Mitrovica. We evaluated BLLs according to ages, sex, and geographical regions.

\section{Laboratory Analysis}

We assessed the lead exposure of the children by measuring lead concentration in blood. Since 2010, these samples are sent to a laboratory in Mitrovica Family Medicine Center (MFMC-AMF), Health and Heavy Metals Unit in Mitrovica, which systematically records data on lead levels in blood tests conducted for screening and follow-up in the Roma community. For BLL greater or equal to $45 \mu \mathrm{g} / \mathrm{dL}$, a further blood lead test was made within 3 weeks, after chelation therapy. For levels of $<45 \mu \mathrm{g} / \mathrm{dL}$, a second test was made within 6 months. "ESA" Lead Analyzer type I and II donated by the European Union (EU), USAID Mercy, was used.

Blood lead analysis was performed in the laboratory in MFMC-AMF using capillary and venipuncture samples tested by anodic stripping voltammetry (ASV) using LeadCare II machines. The highest reported level of lead quantified by this analyzer is $65 \mathrm{mg} / \mathrm{dL}$. Higher levels register as "HIGH." Inclusion criteria were residence in Mitrovica and children younger than 18 years of age.

\section{Ethical Clearance}

The study was approved by the Research Ethics Committee, University of Pristina, Pristina, Kosova.

\section{Statistical Analysis}

All statistical analyses were performed using the Statistical Package for Social Science, SPSS 22.0. Continuous variables are summarized with arithmetic or geometric mean, standard deviation (SD), minimum, and maximum value. Categorical variables are summarized as frequency $(n)$ and percentage (\%). In the statistical analysis, differences between normally distributed continuous variables were tested with the Student's $t$-test and differences between groups with not normally distributed variables were tested with Mann-Whitney test or Kruskal-Wallis test. The Spearman's correlation is calculated with the correlation between BLLs and age. Level of statistical significance was set to $p$-value of $<0.05$.

\section{Results}

The survey included 331 children who at the time of the first measurement were aged 0 to 13 years. - Table 1 shows the general characteristics of the study's subjects. The mean age of the children included in the research was 5.0 years ( $\mathrm{SD} \pm 3.1$ years). Based on the age group, most of the children were 5 to 9 years old, namely 139 or $42.0 \%$, whereas the smaller group was the age group of $<1$ years old, represented with 14 or $4.2 \%$. In terms of gender, 151 children or $45.6 \%$ were females and 180 or $54.4 \%$ were males.

The children involved in the research came from three settlements. The largest number of them, 236 or $71.3 \%$, were from the Roma Mahala and 40 or $12.1 \%$ from the neighborhood 2 Korriku in Mitrovica. From Leposavic, there were 55 or $16.6 \%$. Geometric mean of BLLs was $16.10 \mu \mathrm{g} / \mathrm{dL}$ $(\mathrm{SD} \pm 2.13 \mu \mathrm{g} / \mathrm{dL}$ ). Blood lead values at first measurement were $45 \mu \mathrm{g} / \mathrm{dL}$ in 28 or $8.5 \%$ children, of which 8 or $2.4 \%$ had lead values of 45 to $54 \mu \mathrm{g} / \mathrm{dL}$ and 20 or $6.0 \%$ had lead values of 55 to $69 \mu \mathrm{g} / \mathrm{dL}$ (- Table $\mathbf{1}$ ).

With Spearman's correlation, we did not obtain any significant correlation between age and BLL $(r=-0.07$, $p=0.193$ ). However, at 3 to 4 years the mean BLLs was 
Table 1 General characteristics of the children involved in the research

\begin{tabular}{|c|c|c|}
\hline & $N$ & Percentage \\
\hline Total & 331 & 100.0 \\
\hline \multicolumn{3}{|l|}{ Gender } \\
\hline $\mathrm{F}$ & 151 & 45.6 \\
\hline$M$ & 180 & 54.4 \\
\hline \multicolumn{3}{|l|}{ Age group (y) } \\
\hline$<1$ year & 14 & 4.2 \\
\hline $1-2$ & 72 & 21.8 \\
\hline $3-4$ & 70 & 21.1 \\
\hline $5-9$ & 139 & 42.0 \\
\hline $10-13$ & 36 & 10.9 \\
\hline Age (mean $\pm S D)$ & \multicolumn{2}{|c|}{$5.0 \pm 3.1$} \\
\hline 2 Korriku & 40 & 12.1 \\
\hline Roma Mahala & 236 & 71.3 \\
\hline Leposavic & 55 & 16.6 \\
\hline \multicolumn{3}{|l|}{ First BLL $(\mu \mathrm{g} / \mathrm{dL})$} \\
\hline$<45$ & 303 & 91.5 \\
\hline$\geq 45$ & 28 & 8.5 \\
\hline $45-54$ & 8 & 2.4 \\
\hline $55-69$ & 20 & 6.0 \\
\hline
\end{tabular}

Abbreviations: BLL, blood lead level; F, female; M, male; SD, standard deviation.

higher in comparison with other age groups $(p=0.009)$ (-Fig. 1). In none of the age groups with the Mann-Whitney test did we obtain a significant gender difference $(p>0.05)$ (-Fig. 2).

Mean BLLs were the highest in the Roma Mahala with $23.6 \mu \mathrm{g} / \mathrm{dL}(\mathrm{SD} \pm 15.9 \mu \mathrm{g} / \mathrm{dL})$, then in the neighborhood of 2 Korriku with $15.6 \mu \mathrm{g} / \mathrm{dL}(\mathrm{SD} \pm 10.3 \mu \mathrm{g} / \mathrm{dL})$, and the lowest in children of Leposavic, $12.4 \mu \mathrm{g} / \mathrm{dL}$ (SD $\pm 6.2 \mu \mathrm{g} / \mathrm{dL}$ ). With the Kruskal-Wallis test, we obtained a statistical significance
( $p<0.0001)$ between blood lead values according to settlement (-Fig. 3 ).

\section{Discussion}

Overall, our study revealed that the BLLs of most of the children in Mitrovica registered a poisoning level and need further monitoring.

Although the impact of landfills and the ongoing activities of the Trepça mine and flotation is present not only in the city of Mitrovica but also in the surrounding areas, the most affected by heavy metal poisoning are the residents living in their vicinity, such as the residents of the Roma Mahala, followed by the 2 Korriku neighborhood and Leposavic. Roma Mahala has the largest number of lead-poisoned children and the highest BLLs compared with other neighborhoods, and this is due to the fact that the neighborhood is much closer to the mining sites, and the Roma, Ashkali, and Egyptian (RAE) community lives in the worst economic-social situation, with $95 \%$ of the members of this community unemployed, ${ }^{22}$ and the level of parental education is very low. Blood lead concentrations, average levels $23.6 \pm 15.9 \mu \mathrm{g} / \mathrm{dL}^{-}$, in the children in our study were 3 to 12 times higher than the current average $(1.9 \mu \mathrm{g} / \mathrm{dL})$ of children (ages 1-5 years) in the United States. ${ }^{23}$ In contrary, various scientific research, ${ }^{13,24-26}$ that calculated BLL in children in developing countries, also had similar results to ours.

Various studies $20,21,27,28$ were continuously performed related to BLLs among children in Mitrovica region. The World Health Organization (WHO) has conducted BLL tests from 2004 to 2007, of which the vast majority have resulted with a high BLL. ${ }^{20}$

These results are due to the fact that very little was done by the government to take measures to cleanse the country, exterior soil remediation (overcast removal, covering with clean soil), and closure of factories. Also, people with high BLLs who were removed from certain areas move and do not stay in a clean place. $^{27}$

Another study by WHO was performed in 2004 on 296 children under the age of 4 living in Mitrovica (North and South), several nearby towns (Zveçan, Zubin Potok, and

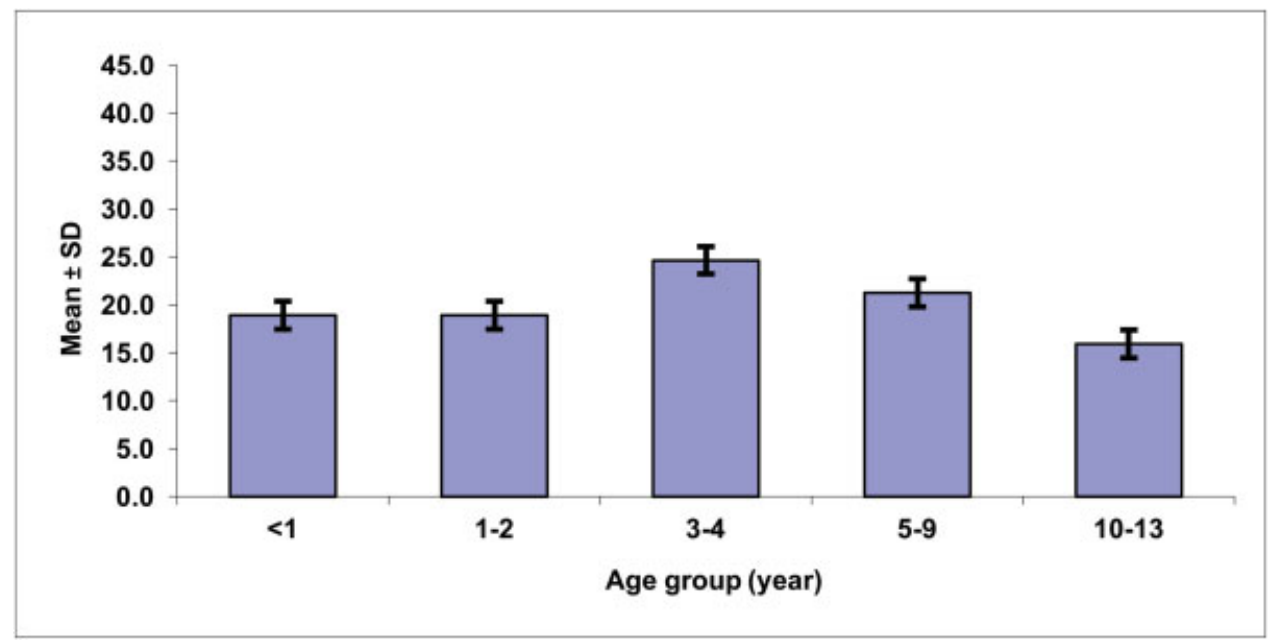

Fig. 1 Blood lead levels ( $\mu \mathrm{g} / \mathrm{dL}$ ) according to age groups. 


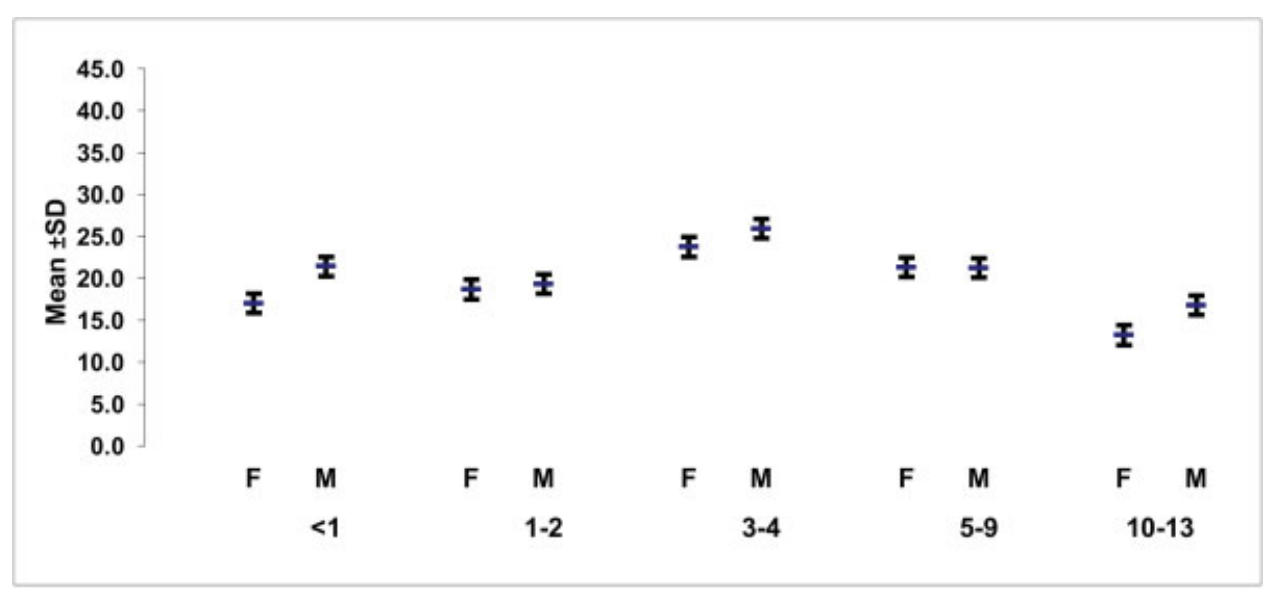

Fig. 2 Blood lead levels $(\mu \mathrm{g} / \mathrm{dL})$ according to age groups and gender.

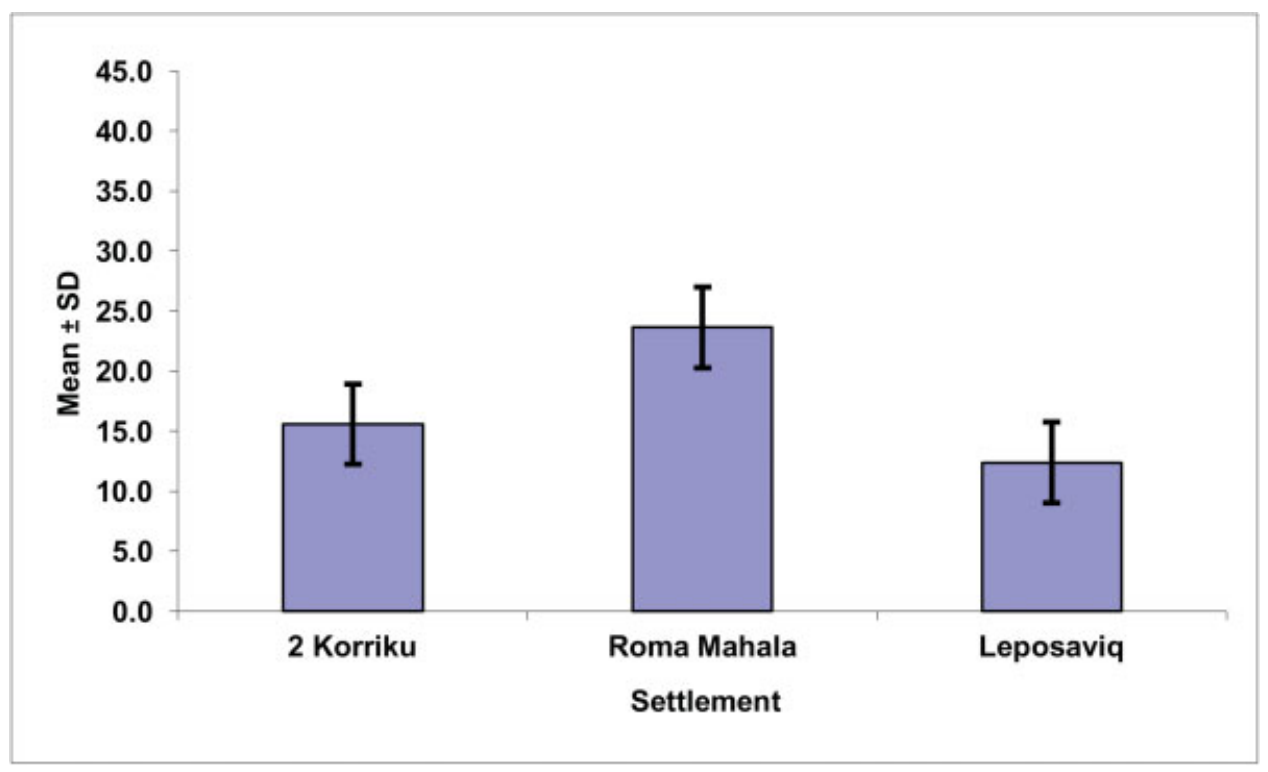

Fig. 3 Blood lead levels $(\mu \mathrm{g} / \mathrm{dL})$ according to settlement.

Leposavic), and in Pristina. ${ }^{27}$ Blood samples from children were analyzed for lead and the following results were obtained: Zveçan (22 children): average BLL $=32.59 \mu \mathrm{g} / \mathrm{dL}$, $\mathrm{SD}=28.67$, and Northern Mitrovica (44 children): average $\mathrm{BLL}=14.32 \mu \mathrm{g} / \mathrm{dL}$, had the highest BLL compared with other cities in Kosova.

Examinations of lead presence in blood in the city of Mitrovica have also been reported by the nongovernmental organization (NGO) "Society for People Under Threat,"28 where most of the examined resulted with high levels of lead in their bloodstream. According to this report, from 2004 to 2008, a total of 602 persons of different ages were examined, of whom 575 had lead in their blood and only 27 were not affected.

Another study shows that 139 out of 240 or around $58 \%$ of examined patients during 2007 in Mitrovica resulted with over $10 \mu \mathrm{g} / \mathrm{dL}$ of BLL. Most of the affected people were aged between 0 and 6 years, and most of them were from "2 Korriku," the neighborhood of the Trepça battery factory, which used to work until $1999 .^{21}$
Examination of persons potentially affected by lead poisoning continued even after 2010 by the MFMC-AMF, a project sponsored by the NGO "Mercy Corps." According to data provided by MFMC-AMF from 2010 to June 2014, a total of 899 persons aged between 1 month and 12 years have been examined, of which 19 resulted in over $45 \mu \mathrm{g} / \mathrm{dL}$ BLL and are still under treatment, whereas the majority resulted in over $10 \mu \mathrm{g} / \mathrm{dL}$ BLL.

It has been a long time since these researches have been conducted, and even these days (current study) comes with the same results that the BLLs of the RAE community are high. However, to bring a small decrease in BLLs, there is a need to support financially the relocation and medical treatment of the residents, including by ensuring that adequate funds are available to relevant Kosovo ministries, and also by ensuring that returnees to the Roma Mahalla have access to welfare, health and education services, security, and access to employment as a matter of priority.

This has been proven by McWeeney. ${ }^{29}$ Lower mean BLLs were found in children born following implementation of the 
interventions as compared with the children born before the interventions. However, this decrease in mean BLLs was attenuated in children born into families suspected of informal lead smelting. Despite lower BLLs following interventions, children living in these camps have BLLs that remain unacceptably high.

Few studies ${ }^{24,30}$ revealed that the BLLs of children showed a decreasing trend after gasoline with lead was banned, or after children received medical intervention, including iron supplementation and improved nutrition, and their mothers received hygienic dietary instructions on how to reduce lead absorption, 5,25,31,32 something that we did not achieve in our study.

From various works it was proved ${ }^{12,30,32}$ that the soil was apparently the principal source to which the children were exposed, because the area where they lived was widely contaminated with lead scrap in the previous decades. It was found that in Mitrovica the average content of lead in the surface soil is $450 \mathrm{mg} / \mathrm{kg}$ (with a range of $35-35,000 \mathrm{mg} / \mathrm{kg}$ ). This lead average exceeded the optimum value specified in the New Dutch list by five times, while it exceeded the EU average value by up to 20 times. $^{17}$

The reason why their BLLs are still high is that a continuous resuspension of dust and dirt particles from the highly contaminated soil around the lead smelter may maintain a very high airborne lead concentration at the breathing height of the children. To mitigate the health problems of those affected, priority criteria were developed to achieve reductions in BLL. ${ }^{33}$ These criteria emphasized education, hygiene, and nutrition.

\section{Study Limitations}

The major strength of this study is its large size. This study also had its limitations. We did not register if children under study received medical intervention, including iron supplementation and improved nutrition, and if their mothers received hygienic dietary instruction on how to reduce lead absorption.

Further research studies including soil, air, and water analysis and their correlation with BLL level among children living in those areas should be conducted. Future health and environmental actions are necessary to investigate other lead contaminated regions.

\section{Conclusion}

The data presented in this study on the increased BLL among children of the Mitrovica region speak best of the emergent need to take concrete steps to remedy the current situation, eliminate pollution sources, and rehabilitate the contaminated sites. Landfills created in the past as well as the current Trepça activities are a major source of pollution and represent a permanent health risk for the city of Mitrovica, in particular the residents living near the landfills. In addition, we recommend three primary prevention strategies for lead poisoning: identify sources, eliminate or control sources, and monitor environmental exposures and hazards.

\section{Authors' Contributions}

The author(s) contributed equally in the preparation of the manuscript.
Conflict of Interest

None declared.

\section{Acknowledgment}

The author(s) would like to thank all the children who participated in this study.

\section{References}

1 Renzetti S, Just AC, Burris $\mathrm{HH}$, et al. The association of lead exposure during pregnancy and childhood anthropometry in the Mexican PROGRESS cohort. Environ Res 2017;152:226-232

2 Schnur J, John RM. Childhood lead poisoning and the new Centers for Disease Control and Prevention guidelines for lead exposure. J Am Assoc Nurse Pract 2014;26(05):238-247

3 Landrigan PJ, Baker EL Jr, Feldman RG, et al. Increased lead absorption with anemia and slowed nerve conduction in children near a lead smelter. J Pediatr 1976;89(06):904-910

4 Lockitch G. Perspectives on lead toxicity. Clin Biochem 1993;26 (05):371-381

5 Shukla V, Shukla P, Tiwari A. Lead poisoning. Indian J Med Specialties 2018;9(03):146-149

6 Huang S, Hu H, Sánchez BN, et al. Childhood blood lead levels and symptoms of attention deficit hyperactivity disorder (ADHD): a cross-sectional study of Mexican children. Environ Health Perspect 2016;124(06):868-874

7 Wang HL, Chen XT, Yang B, et al. Case-control study of blood lead levels and attention deficit hyperactivity disorder in Chinese children. Environ Health Perspect 2008;116(10):1401-1406

8 Koike S. Low-level lead exposure and children's intelligence from recent epidemiological studies in the U.S.A. and other countries to progress in reducing lead exposure and screening in the U.S.A. [article in Japanese]. Nippon Eiseigaku Zasshi 1997;52(03): 552-561

9 Flora SJS, Flora G, Saxena G. Environmental occurrence, health effects and management of lead poisoning. In: Cascas SB, Sordo J, eds. Lead chemistry, analytical aspects, environmental impacts and health effects. Netherlands: Elsevier; 2006:158-228

10 Canfield RL, Henderson CR Jr, Cory-Slechta DA, Cox C, Jusko TA, Lanphear BP. Intellectual impairment in children with blood lead concentrations below 10 microg per deciliter. N Engl J Med 2003; 348(16):1517-1526

11 Yule W, Urbanowicz MA, Lansdown R, Millar IB. Teachers' ratings of children's behaviour in relation to blood lead levels. $\mathrm{Br} \mathrm{J}$ Dev Psychol 1984;2(04):295-305

12 Zejda JE, Sokal A, Grabecki J, Panasiuk Z, Jarkowski M, Skiba M. Blood lead concentrations in school children of Upper Silesian Industrial Zone, Poland. Cent Eur J Public Health 1995;3(02):92-96

13 Childhood Lead Poisoning. World Health Organization; 2010. Available at: http://www.who.int/iris/handle/10665/136571. Accessed June 13, 2019

14 Albalak R, Noonan G, Buchanan S, et al. Blood lead levels and risk factors for lead poisoning among children in Jakarta, Indonesia. Sci Total Environ 2003;301(1-3):75-85

15 Liu J, McCauley L, Compher C, et al. Regular breakfast and blood lead levels among preschool children. Environ Health 2011;10(01):28

16 Musliu A, Shallari S, Hajdini S, Ukaj S, Sinanaj B. Soil pollution in Mitrovica town surroundings as a consequence of mining and industrial processes in Trepca mine. J Int Environ Appl Sci 2012; 12(03):511-514

17 Aliu M, Šajn R, Stafilov T. Spatial distribution of lead in soils of Pb-Zn mining and smelting area of the Mitrovica Region, Republic of Kosovo. J Environ Sci Health A Tox Hazard Subst Environ Eng 2016; 51(07):588-595

18 Factor-Litvak P, Wasserman G, Kline JK, Graziano J. The Yugoslavia Prospective Study of environmental lead exposure. Environ Health Perspect 1999;107(01):9-15 
19 Moreno S, Andrej A "First Phase of Public Health Project on Lead Pollution in Mitrovica Region." United Nations Interim Administration Mission in Kosovo (UNMIK), November 2000:2

20 Kosovo: Poisoned by Lead A Health and Human Rights Crisis in Mitrovica's Roma Camps. Available at: https://www.hrw.org/report/ 2009/06/23/kosovo-poisoned-lead/health-and-human-rights-crisismitrovicas-roma-camps

21 Musliu A, Vitaku A, Veseli B, Strellci S. Lead poisoning and blood lead level in Mitrovica region, Republic of Kosova. J Int Environ Appl Sci 2008;3(04):277-279

22 Office of the Prime Minister. Available at: www.zck-ks.net

23 Soto-Jiménez MF, Flegal AR. Childhood lead poisoning from the smelter in Torreón, México. Environ Res 2011;111(04):590-596

24 He K, Wang S, Zhang J. Blood lead levels of children and its trend in China. Sci Total Environ 2009;407(13):3986-3993

25 Maharaj V. Link between childhood lead poisoning and asthma development and intervention. Epidemiology 2007;18 (05):S194

26 Kutllovci-Zogaj D, Krasniqi S, Elezaj I, et al. Correlation between blood lead level and hemoglobin level in Mitrovica children. Med Arh 2014;68(05):324-328
27 Brown MJ, McWeeney G, Kim R, et al. Lead poisoning among internally displaced Roma, Ashkali and Egyptian children in the United Nations-Administered Province of Kosovo. Eur J Public Health 2010;20(03):288-292

28 Polansky P. Lead poisoning tests summary regarding IDP camps in north Kosovo. Göttingen, Germany: Society for Threatened Peoples; 2009

29 McWeeney G. Draft Risk Assessment from Lead Poisoning in the Region of Mitrovica, Kosovo. Supported by WHO; 2007

30 Espinoza R, Hernández-Avila M, Narciso J, et al. Determinants of blood-lead levels in children in Callao and Lima metropolitan area. Salud Publica Mex 2003;45(Suppl 2):S209-S219

31 Mañay N, Cousillas AZ, Alvarez C, Heller T. Lead contamination in Uruguay: the "La Teja" neighborhood case. In Reviews of Environmental Contamination and Toxicology. New York, NY: Springer; 2008:93-115

32 Ascione AI. Intoxicación porplomoenpediatría. Arch Pediatr Urug 2001;72(02):133-138

33 Roels HA, Buchet JP, Lauwerys R, et al. Lead and cadmium absorption among children near a nonferrous metal plant: a follow-up study of a test case. Environ Res 1978;15(02):290-308 